Ärztliche Erfahrung beschränkt sich nicht auf medizinisches Fachwissen.

Sie entsteht auch aus den mehr oder minder alltäglichen, heiter, ärgerlich oder nachdenklich stimmenden Erlebnissen mit Patienten, Kollegen und Mitarbeitern. Senden Sie uns Ihre Geschichte an: cornelius.heyer@springer.com.

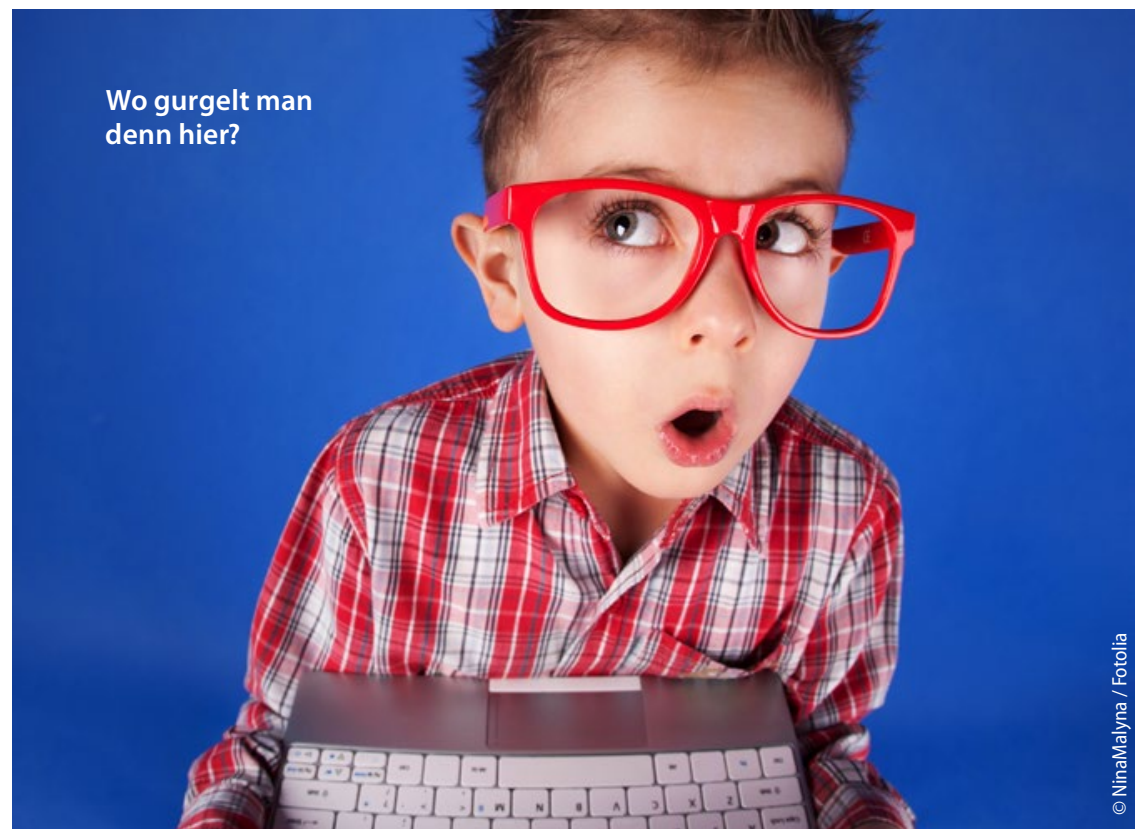

\title{
Gegurgelt wird jetzt im Internet
}

_ Anfang März, zur Grippezeit, waren die Kinderarztpraxen wie gewohnt überfüllt. Ich bekam deshalb mehr Kinder als sonst in meiner Hausarztpraxis zu Gesicht.

In dieser Zeit kam ein achtjähriger Junge mit seinem Vater in die Akutsprechstunde. Er berichtete von Fieber, Husten, Schnupfen und Ohrenschmerzen. Nach der gründlichen Untersuchung, wobei sich bis auf einen geröteten Rachen keine pathologischen Befunde ergaben, empfahl ich dem Vater allgemeine Maßnahmen und schrieb ein Rezept für symptomlindernde und fiebersenkende Medikamente. Dabei erwähnte ich beiläufig, dass auch Gurgeln sinnvoll wäre.

Wir sprachen dann noch über den bevorstehenden Urlaub der Familie, und kurz vor der Verabschiedung fragte mich der Vater noch, womit sein Sohn denn eigentlich Gurgeln sollte. Noch bevor ich antworten konnte, entgegnete der schlaue Junge: „Papa, das ist doch klar! Googeln machen wir mit dem Internet!“

Ich habe ja schon viel von den unerhörten Fortschritten der Telemedizin gehört - aber diese Art der lokalen Anwendung war auch mir neu.

Claudia Krite-Anthes, Springe

\section{Jahre später kommt die Appendix raus}

_ Kurz vor Ende der Sprechstunde kam ein knapp 80-jähriger Patient mit Bauchschmerzen, die seit dem Vortag immer schlimmer geworden waren, in meine Praxis. Die körperliche Untersuchung lenkte den Verdacht rasch auf eine Appendizitis. Ich wies den Patienten sofort ins Krankenhaus ein, wo er noch am selben Tag operiert wurde.

Einige Tage später kam er zur Wundkontrolle und zur Fadenentfernung wieder in die Praxis. „Sie lagen goldrichtig“, rief er freudig aus. „Ich hätte ja nie gedacht, dass das der Blinddarm sein könnte." Er erzählte mir, dass er schon als Fünfjähriger, noch zu Kriegszeiten, mit Verdacht auf Appendizitis im Krankenhaus gelegen hatte. Damals sollte er auch operiert werden, aber dann mussten plötzlich alle Patienten wegen eines Luftangriffs in den Keller fliehen! Er schilderte mir lebhaft die Gerüche und Geräusche jener Tage, sogar an das Krankenhausessen konnte er sich erinnern.

Wie gut, dass wir in Friedenszeiten leben und die Operation des Patienten für das Ärzteteam kein Problem war. Und gleichzeitig traurig zu wissen, dass es vielen anderen Menschen in den Krisengebieten der Welt so ergeht wie meinem Patienten vor über 70 Jahren.

Jonas Hanf, Flensburg 